\title{
SIMULATION OF MODULAR BUILDING CONSTRUCTION
}

\author{
Osama M. Mohsen \\ Paul J. Knytl \\ Basel Abdulaal \\ Jacek Olearczyk \\ Mohamed Al-Hussein \\ 3-015 Markin/CNRL Natural Resources Engineering Facility \\ Department of Civil \& Environmental Engineering \\ Hole School of Construction, University of Alberta \\ Edmonton, AB T6G 2W2, CANADA
}

\begin{abstract}
Modular construction has the advantage of producing structures quickly and efficiently, while not requiring the resources to build a structure to be co-located with the construction site. Large modules can be produced in quality controlled environments, and then shipped to the construction site and assembled with minimal labor requirements. An additional advantage is that once the modules are on-site, construction can proceed extremely quickly. This is ideal for situations where compressed schedules are required in order to meet client's time constraints. This paper examines using software simulation, specifically Simphony.NET, in the design and analysis of the construction process. This is done both before and after project execution to predict productivity and duration and also to allow for exploration of alternate construction scenarios.
\end{abstract}

\section{INTRODUCTION}

The decision to build a project using modular techniques is one often motivated in part by the need to meet strict dead-lines, and builders know that this method will result in a high quality building in a short amount of time. The construction process, however, is still a complicated one due to the various site and crane utilization constraints associated with the task of lifting the large modules. The construction team must have a well-designed plan in place in order to effectively execute the construction; due to time constraints and production sequence factors, there will be little opportunity to modify the sequence of construction once work has begun.

Chehayeb and AbouRizk (1998) make the case for simulation modeling over CPM scheduling. They argue that while the time required to produce a simulation model is higher than that required by traditional CPM techniques, it has advantages in that it allows the project manager to more easily analyze alternate resource and alternate execution scenarios, and in that it allows processes to be modeled stochastically.

Since there is a need to understand the benefits of different construction scenarios, and due to the repetitive nature of the interacting processes, Discreet Event Simulation (DES) is a suitable candidate for by which to evaluate these sorts of modular construction operations. Through the use of a Special Purpose Simulation Software (SPSS) called Simphony, which utilizes a unified modeling methodology, it is possible to develop special purpose models for construction operations (Hajjar and AbouRizk 2002). Using Simphony's General Purpose Simulation template in conjunction with on-site case data, this process can be modeled stochastically. The simulation output provides Cumulative Density Functions (CDFs) for project duration, and provides valuable insight into crew utilization. Using the simulation environment, different scenarios can be tested, and their effect on productivity, duration, and utilization can be estimated.

It should be noted that while $\mathrm{Yu}, \mathrm{Al}-\mathrm{Hussein}$, and Nasseri (2007), as well as Nasereddin, Mullens, and Cope (2007), have investigated the use of DES in improving module production in-factory, the purpose of this paper is to examine the on-site assembly aspect of the modular construction process. 


\section{METHODOLOGY}

\subsection{Model Input}

Selecting the right level of detail for a simulation model is a perennial challenge for researchers; if too much detail is required the model becomes cumbersome and difficult to use, whereas with too little detail the output becomes unreliable. This fact became an obstacle to creating this model.

It should also be noted that weather is an important factor, as with other construction simulations, affecting the ability of the construction crew to make progress in erecting modular projects. In specific, wind and rain affect whether or not work can take place. Because of the presence of openings in the mating surfaces of some of the modules, i.e., stairwells, the buildings must be covered with a tarp to prevent water infiltration from rain. Furthermore, due to the fact that the modules are cranelifted into place and that their orientation must be controlled by personnel on the ground, windy conditions might present a dangerous situation and construction must be halted. However, since accurate weather modeling can be a complicated process, and given that the project's duration is less than two weeks, it was decided in this case that the model should focus primarily on crane, site, and resource restrictions. In reality, unlike with weather these are controllable variables, and they reflect more on the actual production of the system.

The final input parameters are illustrated in Figure 1. The availability of manpower and resources is a typical model input, and this model is no different. In this case, the two main crews involved in erecting the module were a lifting and fitting crew and a welding crew. The construction site had some particular site restrictions in that the project took place in a built-up area which was treed and in which the existing building foundations were in close proximity. Since the crane occupied a position in the centre of the foundations, modules had to be backed into the delivery space individually. As there were no other access roads through the site, this was the only available space for module lay-down, and the occupation of this space would have an effect on production.

Lifting requirements were dependant upon the type of module being placed. Large modules required the use of a spreader bar, while it was decided that small modules would be lifted without the use of this tool. Since the effect of the addition and removal of the spreader bar had an impact on production, these inputs were also included in the model.

The model is stochastic, and as such appropriate statistical distributions are required for most of the task dura- tions. These durations were taken from the final project report and are a mixture of actual durations and expert knowledge. The capacity to change the module arrival sequence and times must also be considered here.

\subsection{Model Processing}

The developed model was built using SIMPHONY.NET simulation tool. The developed model considers building modules as entities that are processed by different resources. Such resources include the crane, fitting crew, welding crew, and the various delivery and installation spots. As each building module arrives on site, it is unwrapped and placed on the delivery spot to be picked up by the crane. For large modules, the spreader bar is first attached to the crane; then, the module is hooked, lifted, and placed in its final position. If the module is a shorter one, the spreader bar is detached and the module is hooked, lifted, and placed in its final position by the crane. Once a module has been placed, the fitting crew must worked to secure and fit the module before welding activities can commence. After setting up all the required modules for one building, the crane is used to lift and place the roof of the building.

Moreover, the model is set to collect statistical information about the average time required for each module to be hooked, lifted, and placed.

\subsection{Model Output}

After running the model, utilization statistics are collected for the above mentioned simulation model. While these are of interest and can lead to suggestions on production improvement, the main metric resulting from running the model is a project duration Cumulative Density Function (CDF) graph. This graph represents the statistical envelope for the project duration, and is useful in making project management decisions and predictions.

According to results obtained from running the simulation model for several iterations, the total duration of the project is expected to be about 4,000 minutes, which is approximately 9 days based on shifts of 8 hours per day. Notably, this is very close to the actual project duration of 10 days. 
Input

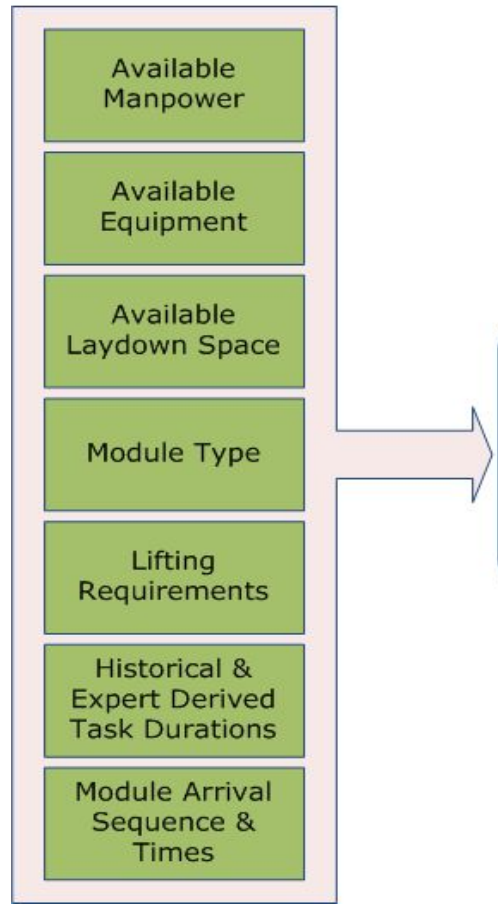

\section{Output}

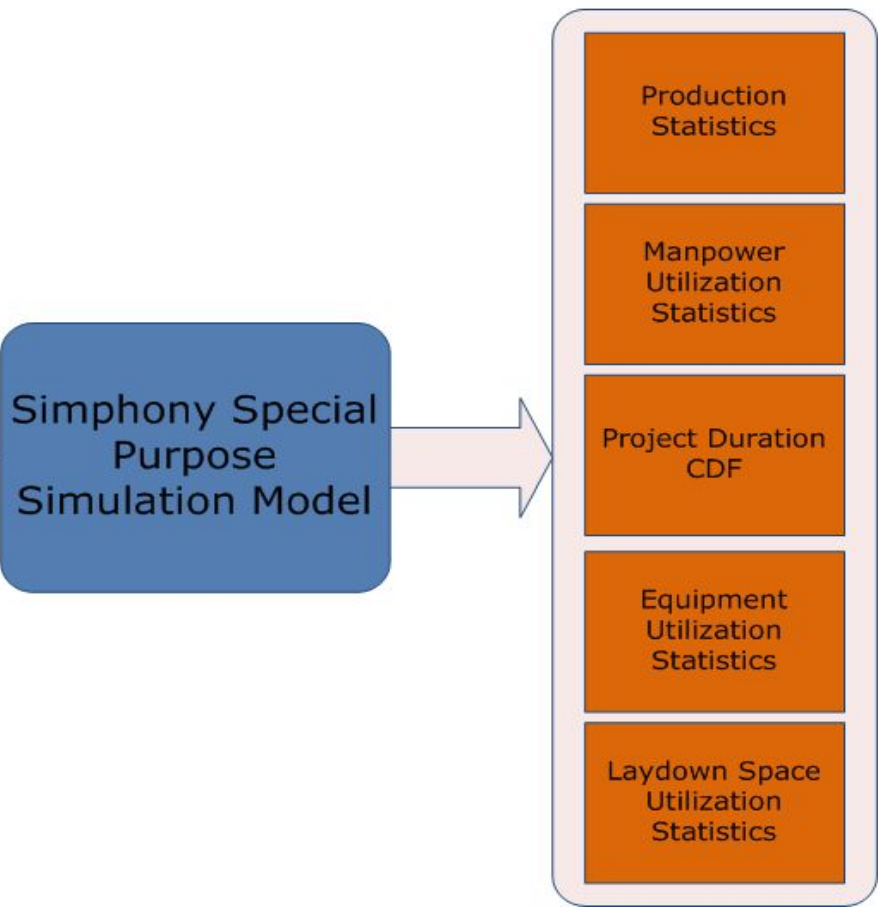

Figure 1: Input and output parameters for the special-purpose model

\section{CASE STUDY}

\subsection{Background}

Five new buildings to be constructed, comprising a dormitory housing 145 students at Muhlenberg College in Allentown, Pennsylvania, were intended to replace a 1981 building accommodating just 56 students. The modular units were manufactured by Kullman Buildings Corp., based in Lebanon, New Jersey, and were delivered to the site on a daily basis. Each dormitory building consists of 18 separate modules, 6 per floor; two small modules (14' width, 22' length, $10^{\prime}$ ' height and a weight of approximately 39,000 lbs.) and four large modules (14', 24', 10' and 42,500 lbs.)

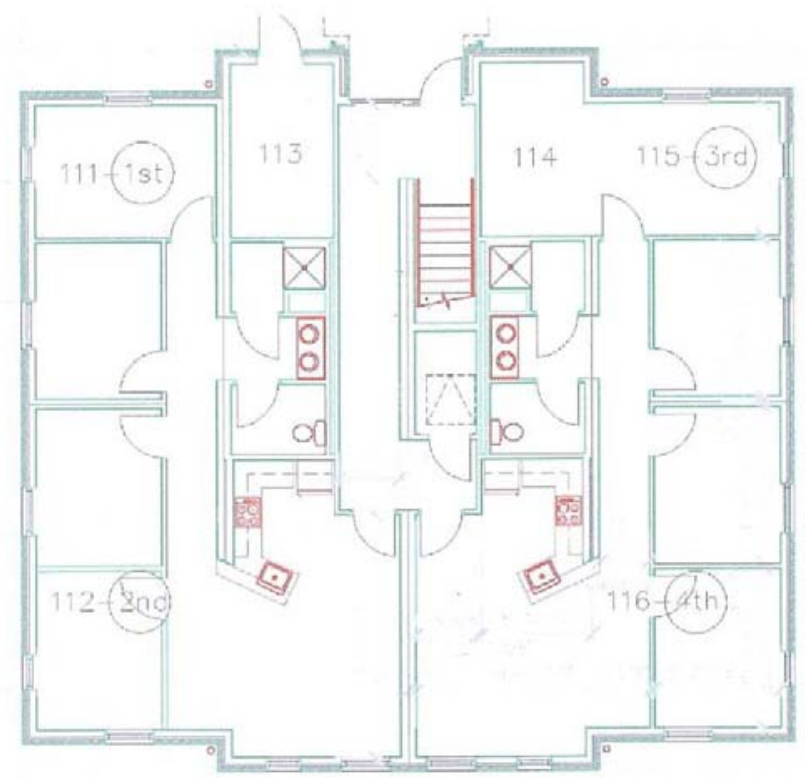

Figure 2: Typical floor-plan for the new building 


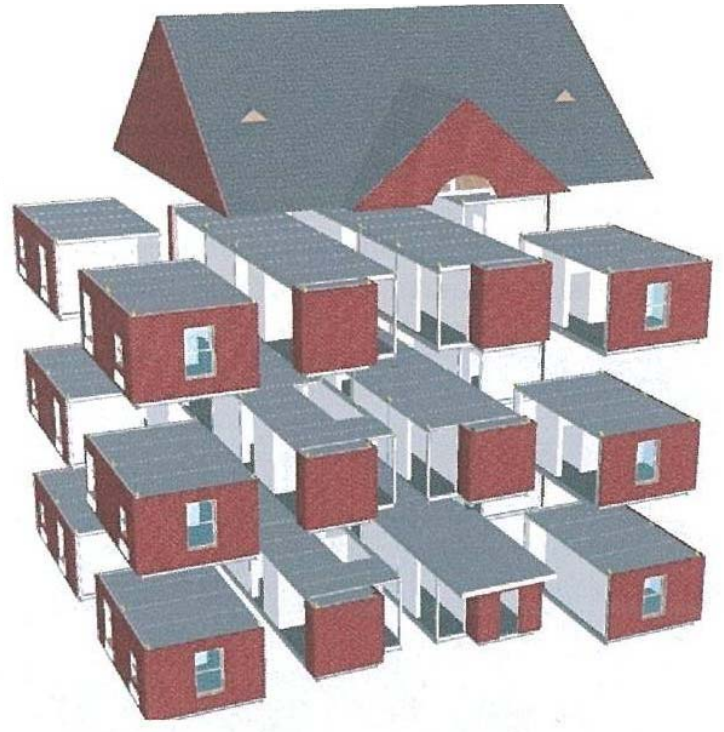

Figure 3: Assembly of the building — exploded view showing the individual modules

\subsection{Research analysis}

Detailed information was gathered during the research phase, prior to building the models and making decisions on the best way to construct the buildings, known collectively as "The Village":

- CAD Modeling Design: kinematics design, 4D simulation and optimization analysis, spreadsheet timing data calculations and records.

- Crane: selection, location, site access analysis, lifting radiuses calculation, extension selection analysis, calculation and record timing of lifting operation.

- Modules: analysis and optimization of each lift, analysis of load travel, lift sequence calculations, spreader bar and link load analyses.

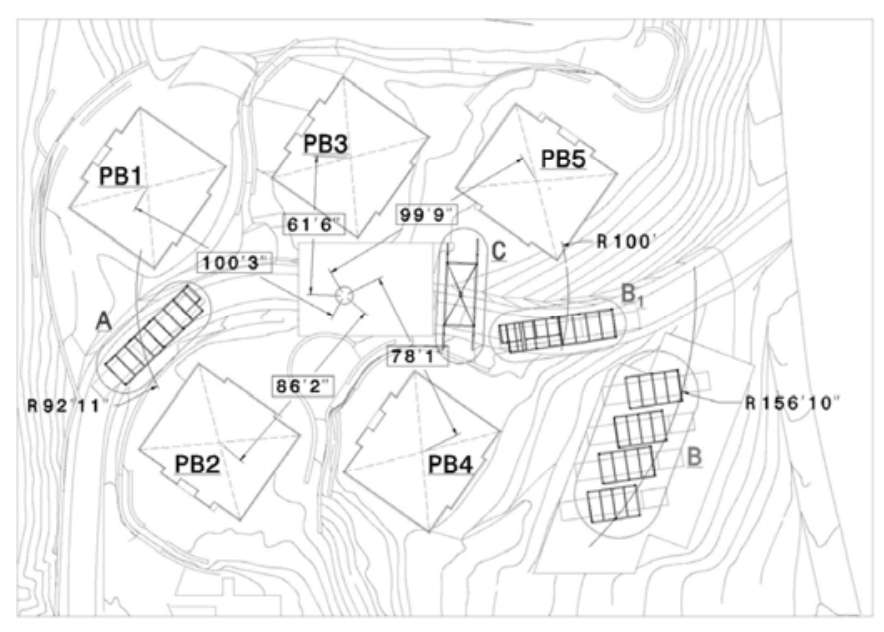

Figure 4: Site layout and crane location

The research stages and collection of results were divided into two phases:

- Phase I: consists of data collection activities, capturing "know-how" and design scenarios. These data would be reflected in flow charts, spreadsheets, detailed schedules, posters, and presentations.

- $\quad$ Phase II: consists of crane lift activities, transportation data including restrictions in terms of time and axle load for Pennsylvania State highways, and information pertaining to terrain complexity and slope profile sections.

Actual operations data collection was carried out June 13-26, 2007, in which special attention was given to tasks of building the roofs. The plan had been to construct and assemble the roofs on the ground and use the crane to lift and install them. Historical weather forecasts for the region in the month of June were also considered.

Figure 4 shows the plan view of the construction site, which was integral in selecting crane and module lay down locations. It illustrates a proposed crane location, the radius to the centroid of each building, and module lay down locations. Labels PB1 through PB5 represent each residence building, while $\mathrm{A}$ and $\mathrm{B}$ are module locations. $\mathrm{C}$ is a proposed location for the spreader bar. Radiuses are also recorded on the figure and are self-explanatory.

\subsection{Mathematical analysis}

Many scenarios were proposed with regard to the sequence of assembling the buildings: i.e., to construct the complex building by building, to construct it floor-byfloor for all buildings simultaneously, or to assemble two buildings at a time. The owner preferred the first scenario proposed due to the given site restrictions. After selecting the scenario for the sequence of module assembly, the primary tasks involved were identified in order to build the simulation model.

Figure 5 shows the crane building assemble flow chart for the approved scenario. B1, A, and D indicate the locations on site where modules were prepared and stored for lifting, and TC indicates the location of the roofs (tennis court). Times and dates of lifting operations are also shown, as well as the details of the usage of the spreader bar. 


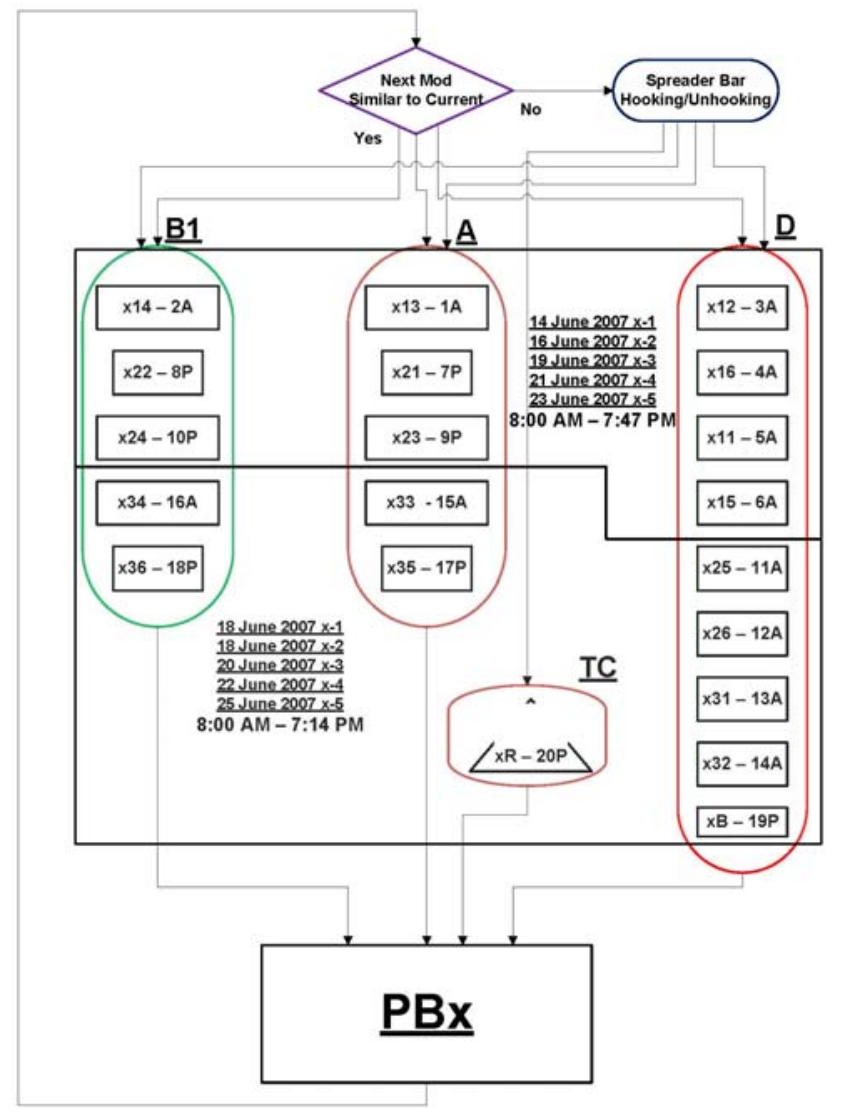

Figure 5: Crane building assembly flow chart of the approved scenario

The arrival time of the modules simulating on site was determined as a Uniform Distribution $(8,10)$, and the total number of Modules was calculated to be 97 , start delivery time was set for $6 / 14 / 2007$, and the end delivery time was set for $6 / 25 / 2007$.

\subsubsection{Lifting sequence analysis}

The welding step was assumed to be the bottleneck of the installation process, and the parallel nature of certain tasks was taken into account in order to obtain a more realistic schedule. Table 1 defines the tasks involved in a repeated cycle of lifting sequences.

Table 1: Model parameters

\begin{tabular}{|l|l|}
\hline Symbol & Indication \\
\hline$H$ & Hooking \\
\hline$C_{o}$ & Crane operation: Booming, swinging, etc \\
\hline$S_{L}$ & Securing and lining \\
\hline$U$ & Unhooking \\
\hline$U_{W}$ & Unwrapping \\
\hline
\end{tabular}

\begin{tabular}{|l|l|}
\hline$S_{B}$ & Spreader bars removal or installation \\
\hline
\end{tabular}

The nature of the assembly dictated that the crane would be the key player in the assembly process. Figure 6 shows the cycle of operations.

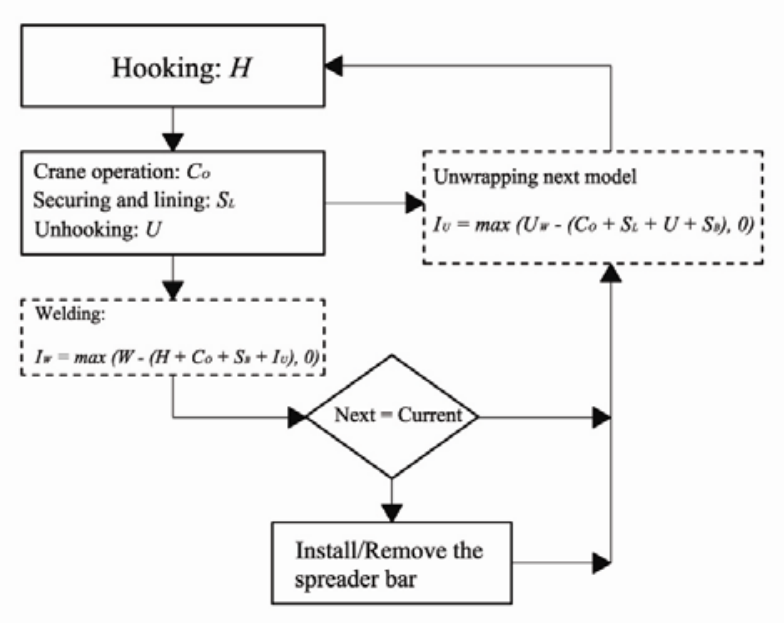

Figure 6: Operation Cycle

The objective function is:

to minimize crane idle time $=\min \left[\sum\left(\mathrm{I}_{\mathrm{U}}+\mathrm{I}_{\mathrm{W}}+\mathrm{S}_{\mathrm{B}}\right)\right]$

$$
\text { where: } \begin{aligned}
\mathrm{I}_{\mathrm{W}} & =\text { Wrapping Time } \\
\mathrm{I}_{\mathrm{U}} & =\text { Unwrapping Time }
\end{aligned}
$$

As per Figure 5, unwrapping and welding operations can be part of the critical path only when the corresponding times are positive. For instance, for unwrapping the time $I_{u}$ needs to be taken into account when

$$
\mathrm{U}_{\mathrm{w}}>\mathrm{U}_{\mathrm{o}}+\mathrm{S}_{1}+\mathrm{U}+\mathrm{S}_{\mathrm{b}}
$$

In a similar manner, the welding time becomes a part of the critical path only when it is greater than

$$
\mathrm{H}+\mathrm{C}_{\mathrm{o}}+\mathrm{I}_{\mathrm{u}}+\mathrm{S}_{\mathrm{b}}
$$

Based on this we can set up a structure model by which to explore the various installation options, the goal always being to minimize crane idle time, which can be summarized as

$$
\operatorname{Min}\left[\sum\left(\mathrm{I}_{\mathrm{u}}+\mathrm{I}_{\mathrm{w}}+\mathrm{S}_{\mathrm{b}}\right)\right]
$$

The time of unwrapping would affect the critical path only when the term

$$
\left.I_{u}=\max \left(C_{o}+S_{1}+U+S_{b}\right), 0\right)
$$


is not equal to 0 .

\subsubsection{Model Operation Coding}

K1- hooking/unwrapping module crew (4 workers)

$\mathrm{T} 1$ - operation for removing empty trailer

$\mathrm{C}$-sb - crane operating with spreader bar attached

K2 - unhooking/securing model crew (2 workers)

$\mathrm{K} 3$ - welding crew (4 welders)

$\mathrm{C}$ - crane operating w/o spreader bar but with slings

$\mathrm{T} 2$ - backing up module flatbed trailer for crane pick-up

$\mathrm{K}$ - Cover Modules for next day work

Activity Dist. Type Parameters

K1 Triangular distribution

$\mathrm{C}$-sb Triangular distribution

T1 Triangular distribution

T2 Triangular distribution

C Triangular distribution

$(19.92,15.07,9.68)$

$(5,7,10) \&(1,2,3)$

$(3,5,7)$

$(3,5,7)$

$(5,7,10) \&(1,2,3)$

K2 Triangular distribution

K3 Triangular distribution

K Triangular distribution

(17.87, 13.51, 9.02)

$(30.69,22.7,17.74)$

$(35,30,28)$

\subsubsection{Start/finish places coding}

B1 - pick up large modules delivered one day in advance $\mathrm{B}$ - parking/storage of small modules one day in advance $\mathrm{C}$ - temporary holding for spreader bar between operations

A -pick up modules delivered during lifting operation PB1-1 - building number - floor number

Micro movements of the crane and the other related activities constitute the backbone of the of the model. Figure 7 shows the activity data collected and compiled in spreadsheets which serve as the basis for the building of the simulation model.

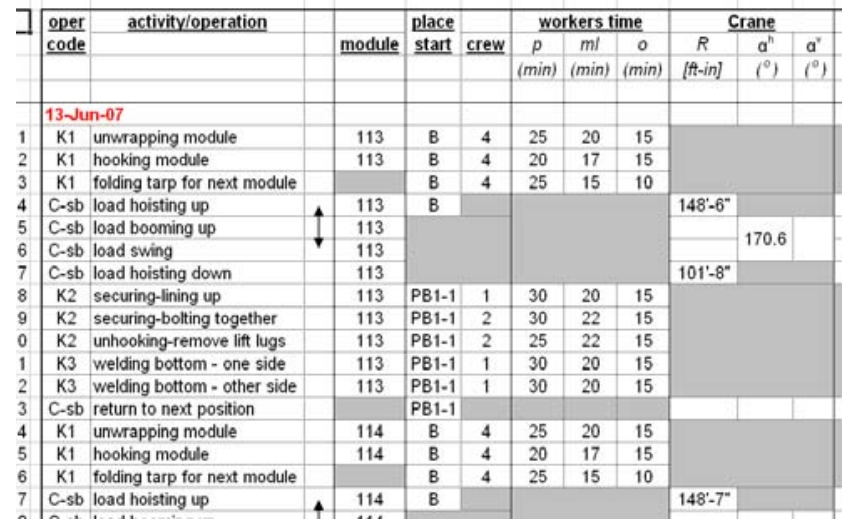

Figure 7: Activities database

After building and running the simulation model in the Simphony environment, statistical results were collected:

- One building completion 780 mins. (13 hrs.)

- $\quad$ Time each model spent in the system 44 mins. (0.73 hr.)

- $\quad$ Total time for project completion 3900 mins. (65 hrs.)

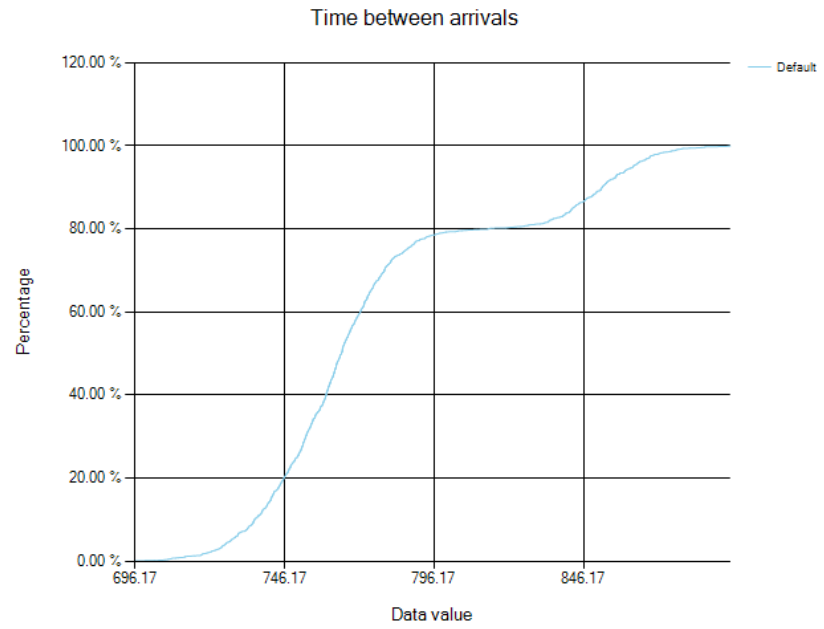

Figure 8: $\mathrm{CDF}$ for individual building erection times (in minutes)

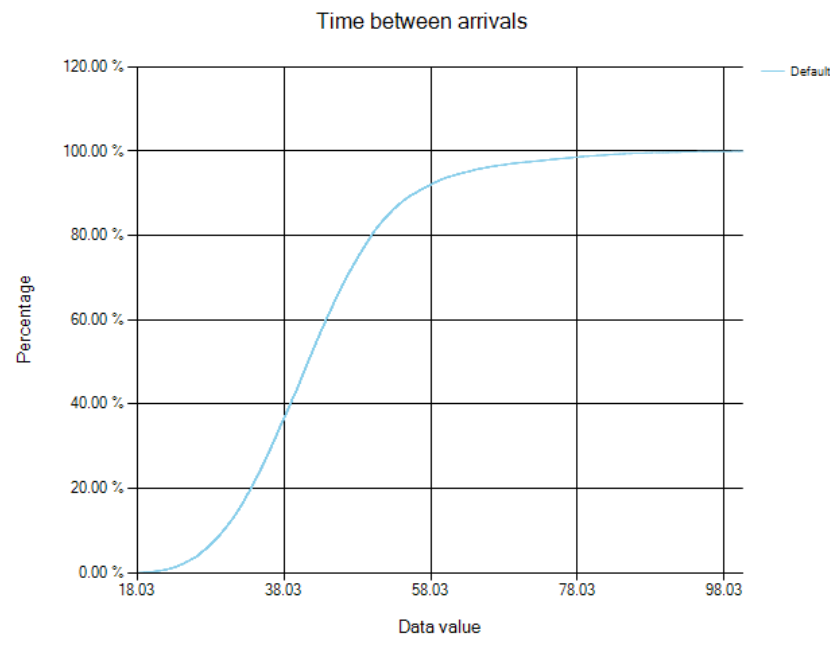

Figure 9: CDF for erection times of individual models (in minutes) 


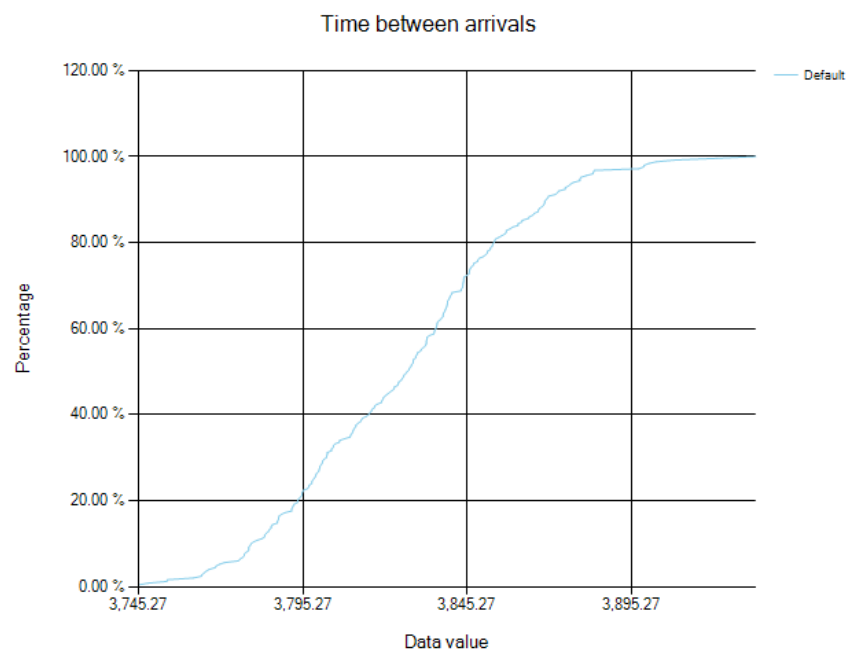

Figure 10: CDF representing the total duration of the erecting of all buildings in the project (in minutes)

A comparison between our model results and the actual utilization of the data collected during construction is shown in Table 2.

Table 2: Utilization of resources

\begin{tabular}{|c|c|c|}
\hline \multirow{2}{*}{ Resource } & \multicolumn{2}{|c|}{ Utilization } \\
\cline { 2 - 3 } & Simphony Model & $\begin{array}{c}\text { In Real Life } \\
\text { Construction }\end{array}$ \\
\hline Crane & $83.78 \%$ & $91 \%$ \\
\hline Rigging Crew & $85.09 \%$ & $87 \%$ \\
\hline Welding Crew & $59.17 \%$ & $78 \%$ \\
\hline Delivery Space & $100 \%$ & $100 \%$ \\
\hline
\end{tabular}

\section{CONCLUSIONS}

Identifying the activities and their durations was the first essential step in data collection, and this process assisted both in building the simulation model and in allocating an adequate amount of time to building the CAD model and analyzing the lift sequences and locations; it also helped to lessen and prevent unpredicted errors.

Taking into consideration all aspects and elements of the model and the components of the project at an early stage will ensure accurate results and proper management of resources such that delays in the delivery of the final product may be circumvented.

An output analysis of the model shows that crane, fitting crew, and delivery space utilization were used effectively despite the time constraint which in some cases prevented the attainment of a higher level of utilization.

The advantage of proceeding quickly at the construction site was achieved with the help of the simulation model, which served to meet the constraints imposed on the project due to tight scheduling.

\section{ACKNOWLEDGEMENT}

This research work was conducted in participation with Kullman Building Corp., as they allowed the use of their historical data and accommodated our monitoring of the progress of the research.

We are also deeply indebted to Dr. Mohamed AlHussein, an Associate Professor at the University of Alberta, who supervised the research, as well as to Dr. Ahmed Bouferguene, from the Campus Saint-Jean at the University of Alberta for his mathematical input regarding the utilization of algorithms in this research.

\section{REFERENCES}

Chehayeb, N. and S. AbouRizk. 1998. Simulation-Based Scheduling with Continuous Activity Relationships. Journal of Construction Engineering and Management, ASCE, 124: 107-115.

Hajjar, D. and S. AbouRizk. 2002. Unified Modeling Methodology for Construction Simulation. Journal of Construction Engineering and Management, ASCE, 128(2): 174-185.

Nasereddin, M., M. Mullens, and D. Cope. 2007. Automated Simulator Development : A Strategy for Modeling Modular Housing Production. Automation in Construction, 16(2): 212-223.

Olearczyk, J., M. Al-Hussein, A. Bouferguene, and A. Telyas. 2007. Crane Layout Optimization for Five New Student Residence Buildings at Muhlenberg, MacGregor Village in Allentown, Pennsylvania. Muhlenberg College, Final report (August 2007).

Yu, H., M. Al-Hussein, and R. Nasseri. 2007. Process Flowcharting And Simulation Of House Structure Components Production Process. Proceedings of the 2007 Winter Simulation Conference, ed S. G. Henderson, B. Biller, M.-H. Hsieh, J. Shortle, J. D. Tew, and R. R. Barton, 2066-2072.

\section{AUTHOR BIOGRAPHIES}

OSAMA M. MOHSEN is a Graduate Student in the Department of Civil and Environmental Engineering at the University of Alberta. He received his B.Sc. degree in Architectural Engineering from King Fahd University of Petroleum and Minerals, Saudi Arabia. His recent research 
interests include simulation of construction operations, and the application of automation and context-aware computing in construction field activities. He is a student member of ACI (American Concrete Institute).

PAUL J. KNYTL is an M.Sc. student at the Hole School of Construction Engineering and Management at the University of Alberta in Edmonton, Alberta, Canada. He received his B.Sc. in Civil Engineering from the University of Alberta in 2007. His research interests include modular construction, building information modeling, and construction simulation. Mr. Knytl is also a student member of APEGGA and the CSCE.

BASEL ABDULAAL is a graduate student in the Department of Civil and Environmental Engineering, University of Alberta. Mr. Abdulaal specializes in threedimensional, Solid Model in CAD, and Health care building design. Mr. Abdulaal research work is focusing on hospital operational simulation and optimization. He has extensive experience in design and operation analysis as well as in project management.

JACEK OLEARCZYK is a graduate student in the Department of Civil and Environmental Engineering, University of Alberta. Mr. Olearczyk specializes in threedimensional, kinematics and analysis of equipment design, focusing on converting ideas and verbal descriptions of complex prototypes into solid models, threedimensional renderings and detailed fabrication drawings for research, fabricators and operators.

MOHAMED AL-HUSSEIN is an Associate Professor at the Hole School of Construction Engineering and Management, University of Alberta. Dr. Al-Hussein's research interests have been in project and construction management, and he has significant research in computer modeling with regard to business process modeling and data modeling in construction; in particular, this has included utilization of 3D-CAD modeling, object oriented methodology, and information management systems. Dr. AlHussein is also an accomplished and well-published scholar in his field. 